Document heading doi: 10.21276/apjhs.2019.6.12

Original Research Article

\title{
Association of body mass index with pulmonary function parameters in females with non- obstructive airway disease identified by spirometric protocols attending Bankura Sammilani Medical College
}

\author{
Susanta Gorai ${ }^{1}$, Writtika Chattaraj ${ }^{2 *}$, Debasis Pramanik \\ ${ }^{1}$ Demonstrator, Department of Physiology, Bankura Sammilani Medical College, Bankura Sammilani \\ Medical College Road, Kenduadihi, Bankura, West Bengal 722102, India \\ ${ }^{2}$ Assistant Professor, Department of Physiology, Diamond Harbour Govt. Medical College, Harindanga, \\ Diamond Harbour, South 24 Parganas, West Bengal 743331, India \\ ${ }^{3}$ Professor, Department of Physiology, Bankura Sammilani Medical College, Bankura Sammilani \\ Medical College Road, Kenduadihi, Bankura, West Bengal 722102, India
}

Received: 06-09-2019 / Revised: 25-10-2019 / Accepted: 29-10-2019

\begin{abstract}
Background: The effect of body mass index (BMI) on the incidence and prevalence of airway obstructive diseasesasthma, chronic bronchitis, and emphysema - is not clear. The nature of the relationship between BMI and airway obstructive diseases are also complicated by the potential effect respiratory symptoms can have on appetite and physical activity. Aims: Proposed study was to find out the association between body mass index and lung functions in females with Non-obstructive airway disease identified by spirometric protocols. Materials and Methods: A retrospective analysis of the spirometry data obtained between August 2018 and January 2019 was conducted in the Physiology Department, B. S. Medical College, Bankura for six months. In this study above 200 test results over female subjects were taken from study database. Out of those 138 test results of Non-obstructive airway disease were included considering inclusion and exclusion criteria. Results: The Study shows PEFR and FEF75\% have significant positive correlation with BMI of underweight. But in normal subject's significant positive correlation between FEV1/FVC, FEF25-75\%, PEFR, PIFR, FEF25\%, and FEF50\% with BMI were observed. In overweight there were significant negative correlation observed between FEV1, FEF25-75\%, PIFR and FEF50\% with BMI. Conclusion: Our study showed that clear association was found between pulmonary function parameters and BMI in females with non-obstructive airway disease.
\end{abstract}

Key word: BMI, Pulmonary functions, Non-obstructive airway, Underweight, Overweight

(C) The Author(s). 2019 Open Access. This work is licensed under a Creative Commons Attribution. The full terms of this license are available at our website and incorporate the Creative Commons Attribution. https://creativecommons.org/licenses/by/4.0/

\section{INTRODUCTION}

In India, not only obesity but also undernutrition is prevalent. Undernutrition is not a disease state and can be managed with proper nutritional therapy. ${ }^{[1]}$ On the other hand, obesity is a global problem and it is a significant contributor to morbidity and mortality. ${ }^{[2]}$ The effect of body mass index (BMI) on the incidence and prevalence of airway obstructive diseases -asthma,

\section{*Corresponding Author}

\section{Dr. Writtika Chattaraj}

Assistant Professor, Department of Physiology, Diamond Harbour Govt. Medical College,

Harindanga, Diamond Harbour,

South 24 Parganas, West Bengal, India- 773331

E-mail: drwrittikachattaraj@gmail.com chronic bronchitis, and emphysema- is not clear. The nature of the relationship between BMI and airway obstructive diseases are also complicated by the potential effect respiratory symptoms can have on appetite and physical activity. For example, subjects with airway obstructive diseases may be more likely to avoid exercise, adopt a sedentary lifestyle and, in turn, gain weight. An association between obesity and asthma has been reported widely, with disparity between males and females. The magnitude of increase in obesity has been paralleled by an increase in the prevalence of asthma in many global locales. ${ }^{[2,3]}$

A study done by Beuther and Sutherland the effect of elevated body mass index (BMI) on asthma incidence determined that the likelihood of asthma was 1.51 
times higher in subjects with a BMI $\geq 25 \mathrm{~kg} / \mathrm{m} 2$ compared to those of a normal weight (18.5-24.9 $\mathrm{kg} / \mathrm{m}^{2}$ ) \{Odds Ratio (OR) $1.51,95 \%$ CI, 1.17-1.62\}. ${ }^{[4]}$ Various studies are also suggestive of an increased prevalence of obesity amongst adults with asthma, but do not adequately describe any cause and effect relationship between the obesity and asthma. ${ }^{[5,6,7]}$ Various studies that investigated the association of obesity and airway responsiveness where the association between asthma and obesity was not found. ${ }^{[8,9,10]}$ The relationship to an abnormal BMI has been more extensively studied for asthma than COPD. Higher levels of BMI and higher proportions of obese subjects have been found among patients with asthma than control subjects in adult populations. ${ }^{[11,12]}$ Proposed study was to find out the associationbetween body mass index and lung functions in females with Non-obstructive airway disease identified by spirometric protocols.

\section{MATERIAL AND METHODS}

In this study above 200 test results over female subjects were taken from study database. Out of those 138 test results of non-obstructive airway disease were included considering inclusion and exclusion criteria. Written informed consent from every patient was already taken. Ethical approval was granted by the Ethics committee of Bankura Sammilani Medical College, Bankura, West Bengal.

Experimental Protocol: A retrospective analysis of the spirometry data obtained between August 2018 and January 2019 was conducted in the Physiology Department, B. S. Medical College, Bankura for six months. Patients were selected from those participants, referred to the pulmonary function laboratory in the Department of Physiology by a variety of medical specialties including Chest Medicine, General Medicine, Paediatric medicine General Surgery, Gynaecology, Oncology, etc. The treatment sheets of every patient referred by physicians were consulted for their relevant history, examination finding, and investigation so also the pulmonary functions test results. The cases under review were selected on the basis of : a) < 12\% improvement in FEV1 after reversibility test, b) FEV1 $\geq 80 \%$ of predicted without reversibility test and c) FEV1 $<80 \%$ of predicted but with FEV1/FVC $\geq 70 \%$ of predicted without reversibility test. The exclusion criteria were a) $\geq 12 \%$ improvement in FEV1 after reversibility test b) FEV1 $<80 \%$ of predicted without reversibility test and c) FEV $1<80 \%$ of predicted and FEV1/FVC $<70 \%$ of predicted without reversibility test, d) subjects with any cardiac ailments.
Measurement of Anthropometric parameters Weight was measured using a standardized electronic weighing machine, with the subjects standing without footwear, carrying any bagwith light clothes. The height of the subjects were measured to the nearest centimetre using stadiometer, Body Mass Index (BMI) was calculated by using Quetlet's index (body weight in $\mathrm{kg} /$ height in $\left.\mathrm{m}^{2}\right) .{ }^{[13]}$ Depending on their BMI values, the subjects were classified into underweight $\left(\mathrm{BMI}<18.5 \mathrm{~kg} / \mathrm{m}^{2}, \mathrm{n}=21\right)$, normal $\left(18.5\right.$ to $<25 \mathrm{~kg} / \mathrm{m}^{2}$, $\mathrm{n}=63)$ and overweight $\left(>25 \mathrm{~kg} / \mathrm{m}^{2}, \mathrm{n}=54\right)$ groups according to BMI ranges as per WHO classification system. ${ }^{[2]}$

\section{Measurement of the Pulmonary Functions}

Pulmonary functions were measured by the electronic spirometer, model-RMS Helios-702 in accordance with the standards of lung function testing of the American Thoracic Society/European Respiratory Society (ATS/ERS). ${ }^{[14]}$ Test was measure between 10 a.m. to 12 p.m. to avoid any circadian rhythm. The subjects were asked to avoid beverages like tea, coffee and other stimulants and to report on a light breakfast. The test was explained and demonstrated to the subjects. After a rest for 5-10 minutes, the test was carried out. The best of the three acceptable results was selected. Post bronchodilator (reversibility test) testing was performed 10 minutes after administration of the bronchodilator. Pulmonary function report included patient's gender, height, weight, age and smoking status. Standard spirometric measures included, forced vital capacity (FVC), forced expiratory volume in one second FEV1, the ratio of forced expiratory volume in one second to forced vital capacity (FEV1/FVC), Forced Expiratory Flow in 25-75\% (FEF25\%75\%),Peak Expiratory Flow Rate (PEFR), Peak Inspiratory Flow Rate (PIFR), Forced Expiratory Flow in $25 \%$ (FEF25\%), Forced Expiratory Flow in 50\% (FEF50\%) and Forced Expiratory Flow in $75 \%$ (FEF75\%). Pulmonary function variables were recorded as a percentage of the normal value predicted on reported height and age. ${ }^{[15]}$

\section{Statistical Analysis}

Descriptive data analysis included the use of Mean and Standard Deviation was done. Data were analysed by SPSS (Statistical Package for Social Sciences) statistical software version 22 using proper statistical test. Differences were considered statistically different when $\mathrm{p}<0.05$.

\section{RESULTS}

Descriptive analysis was done of pulmonary function parameters of all female. Mean and standard deviation of female were calculated [Table 1]. Pulmonary function parameters were slightly higher in normal
Gorai et al

www.apjhs.com 
comparison to underweight and overweight (except PIFR).

[Table 2] shows PEFR and FEF75\% have significant positive correlation with BMI of underweight and there is lack of association between FVC, FEV1, FEV1/FVC, FEF25-75\%, PIFR, FEF25\%, and FEF $50 \%$ with BMI. But in normal subject's significant positive correlation between FEV1/FVC, FEF25-75\%,
PEFR, PIFR, FEF25\%, and FEF50\% with BMI were observed. There is lack of association between FVC, FEV1, and FEF75\% with BMI [Table 2]. In overweight there were significant negative correlation observed between FEV1, FEF25-75\%, PIFR and FEF50\% with BMI. There is lack of association between FVC, FEV1/FVC, PEFR, FEF25\% and FEF75\% with BMI [Table 2].

Table 1: Mean and standard deviation of pulmonary function parameters of all females

\begin{tabular}{|c|c|c|c|}
\hline $\begin{array}{l}\text { Pulmonary } \\
\text { function } \\
\text { parameters } \\
\text { of all female }\end{array}$ & $\begin{array}{c}\text { Underweight } \\
(\mathrm{n}=21) \\
\left(\mathrm{BMI}<18.5 \mathrm{~kg} / \mathrm{m}^{2}\right. \\
)\end{array}$ & $\begin{array}{l}\text { Normal weight }(\mathrm{n}=63) \\
(\mathrm{BMI} 18.5 \text { to } \\
\left.<25 \mathrm{~kg} / \mathrm{m}^{2}\right)\end{array}$ & $\begin{array}{l}\text { Overweight }(\mathrm{n}=54) \\
\left(\mathrm{BMI}>25 \mathrm{~kg} / \mathrm{m}^{2}\right)\end{array}$ \\
\hline$(n=138)$ & Mean \pm SD & Mean \pm SD & Mean \pm SD \\
\hline $\mathrm{FVC}(\mathrm{L})$ & $1.78+0.31$ & $2.10 \pm 0.48$ & $2.05 \pm 0.34$ \\
\hline FEV1 (L) & $1.59 \pm 0.18$ & $1.93 \pm 0.52$ & $1.79 \pm 0.27$ \\
\hline FEV1/FVC (\%) & $90.84 \pm 8.02$ & $91.37 \pm 7.40$ & $87.55 \pm 5.83$ \\
\hline FEF $25-75(\mathrm{~L} / \mathrm{s})$ & $2.17 \pm 0.56$ & $2.63 \pm 0.99$ & $2.19 \pm 0.51$ \\
\hline PEFR (L/s) & $4.53 \pm 0.82$ & $4.53 \pm 1.05$ & $4.24 \pm 1.45$ \\
\hline PIFR (L/s) & $2.87 \pm 0.67$ & $2.43 \pm 1.04$ & $2.57 \pm 1.20$ \\
\hline FEF $25 \%(\mathrm{~L} / \mathrm{s})$ & $3.96 \pm 0.78$ & $4.15 \pm 1.02$ & $3.68 \pm 0.98$ \\
\hline FEF 50\% (L/s) & $2.61 \pm 0.59$ & $3.03+1.03$ & $2.61 \pm 0.63$ \\
\hline FEF 75\% (L/s) & $1.17 \pm 0.48$ & $1.47 \pm 0.72$ & $1.14 \pm 0.41$ \\
\hline
\end{tabular}

Table 2: Correlation between Pulmonary function parameters and Body mass index (BMI) of all females

\begin{tabular}{|c|c|c|c|}
\hline \multicolumn{2}{|c|}{$\begin{array}{l}\text { Correlation of Pulmonary function parameters } \\
\text { with Body mass index(BMI) of all female }(n=138)\end{array}$} & \multirow{2}{*}{$\begin{array}{l}\text { Pearson Correlation } \\
\text { Coefficient(r) } \\
.081\end{array}$} & \multirow{2}{*}{$\begin{array}{r}\text { p value } \\
0.728\end{array}$} \\
\hline Underweight $(\mathrm{n}=21)$ & $\mathrm{FVC}(\mathrm{L})$ & & \\
\hline$\left(B M I<18.5 \mathrm{~kg} / \mathrm{m}^{2}\right)$ & FEV1 (L) & .177 & 0.443 \\
\hline & FEV1/FVC (\%) & .092 & 0.691 \\
\hline & FEF 25-75 (L/s) & .105 & 0.652 \\
\hline & $\operatorname{PEFR}(\mathrm{L} / \mathrm{s})$ & $.466^{*}$ & 0.033 \\
\hline & PIFR (L/s) & .282 & 0.215 \\
\hline & FEF $25 \%(\mathrm{~L} / \mathrm{s})$ & .239 & 0.298 \\
\hline & FEF $50 \%(\mathrm{~L} / \mathrm{s})$ & .161 & 0.486 \\
\hline & FEF $75 \%(\mathrm{~L} / \mathrm{s})$ & .029 & 0.001 \\
\hline \multirow{9}{*}{$\begin{array}{l}\text { Normal } \\
\text { weight }(\mathrm{n}=63) \\
\left(\text { BMI } 18.5 \text { to }<25 \mathrm{~kg} / \mathrm{m}^{2}\right)\end{array}$} & $\mathrm{FVC}(\mathrm{L})$ & -.215 & 0.090 \\
\hline & FEV1 (L) & -.096 & 0.453 \\
\hline & FEV1/FVC (\%) & $.388^{* *}$ & 0.002 \\
\hline & FEF 25-75 (L/s) & $.269^{*}$ & 0.003 \\
\hline & $\operatorname{PEFR}(\mathrm{L} / \mathrm{s})$ & $.356^{* *}$ & 0.004 \\
\hline & PIFR (L/s) & $.295^{*}$ & 0.019 \\
\hline & FEF $25 \%(\mathrm{~L} / \mathrm{s})$ & $.391^{* *}$ & 0.002 \\
\hline & FEF $50 \%(\mathrm{~L} / \mathrm{s})$ & $.276^{*}$ & 0.029 \\
\hline & FEF $75 \%(\mathrm{~L} / \mathrm{s})$ & .150 & 0.241 \\
\hline \multirow{2}{*}{$\begin{array}{l}\text { Overweight }(\mathrm{n}=54) \\
\left.\text { BMI }>25 \mathrm{~kg} / \mathrm{m}^{2}\right)\end{array}$} & $\mathrm{FVC}(\mathrm{L})$ & -.243 & 0.077 \\
\hline & FEV1 (L) & $-.320^{*}$ & 0.018 \\
\hline
\end{tabular}




\begin{tabular}{|c|l|r|r|}
\hline \multirow{5}{*}{} & FEV1/FVC (\%) & -.132 & 0.342 \\
\cline { 2 - 4 } & FEF 25-75 (L/s) & $-.297^{*}$ & 0.029 \\
\cline { 2 - 4 } & PEFR (L/s) & -.150 & 0.280 \\
\cline { 2 - 4 } & PIFR (L/s) & $-.598^{* *}$ & 0.000 \\
\cline { 2 - 4 } & FEF 25\% (L/s) & -.203 & 0.142 \\
\cline { 2 - 4 } & FEF 50\% (L/s) & $-.371^{* *}$ & 0.006 \\
\cline { 2 - 4 } & FEF 75\% (L/s) & -.178 & 0.197 \\
\hline
\end{tabular}

\section{DISCUSSION}

The result of this study indicated a significant positive correlation between lung functions in terms of PEFR and FEF75\% with BMI in underweight individual. Undernutrition is responsible for decrease in expiratory and inspiratory muscle mass, thus weakening the respiratory muscle. Weaker respiratory muscle diminishes the ventilatory capacity. Undernutrition also decreases the defence mechanism of respiratory system. ${ }^{[16]}$ Ong et al. also studied the lung functions in malnourished children, and they found that there is a positive correlation between lung function and body weight. ${ }^{[17]}$ There was no significant correlation between BMI and pulmonary function test parameters in normal and overweight boys. This result is concordant with the study of Muralidhara and Bhat who also found no significant correlation between BMI and pulmonary function. ${ }^{[18]}$ However, the result of this study is not corroborative with the result of Wannamethee et al. who found inverse relationship between BMI and most pulmonary function in overweight and obese individuals. ${ }^{[19]}$

Recent findings from the Baltimore Longitudinal Study of Aging suggest that low BMI could itself be a risk factor for COPD. ${ }^{[20]}$ In another study, underweight patients with COPD were found to have lower carbon monoxide diffusing capacity and higher dyspnea scores than normal weight patients with COPD. ${ }^{[21]}$ These characteristics are traditionally attributed primarily to the more emphysematous form of COPD. ${ }^{[22]}$ Emphysema patients can progressively lose weight due to several mechanisms. For instance, it has been hypothesized that the oxygen cost of breathing is increased in these patients and the caloric intake is reduced since large meals can induce shortness of breath. ${ }^{[23,}{ }^{24]}$ The effects of obesity on spirometric values are not consistent in most of the studies, some studies showing significant effects ${ }^{[25-28]}$ and some other studies showing no effects. ${ }^{[29,30,31]}$ This discrepancy between studies could be explained by the wide variations in ethnicity of different population in PFT values or this may be a result of methodological differences in these studies. Our study significant positive correlation between FEV1/FVC, FEF25-75\%, PEFR, PIFR, FEF25\%, and FEF50\% with BMI were observed in normal females. The compromised FVC, FEV1, FEV1/FVC, and uncompromised expiratory flow rates together suggestive of the dominant effects of increasing BMI on chest wall restriction and diaphragmatic limitation. We have also allowed for the isolation of this effect by inclusion of only nonobstructive airway disease participants. If obstructive airway disease like asthma, chronic bronchitis were present in this subject pool, then we anticipate that airway obstruction would be exaggerated by the reduced lung volumes. Our findings demonstrate a marginal increase in airflow secondary to chest wall impedance.

Study show significant negative correlation between FEV1, FEF25-75\%, PIFR and FEF50\% with BMI in overweight females. Schoenberg et al. reported that increase in muscle mass initially increases the pulmonary functions, but subsequent increase in weight may actually restrict the chest wall movement and thus may decrease the parameters. ${ }^{[32]}$ The result of our study supports the study by Saxena et al., who found insignificant group difference between normal and over weight participants. ${ }^{[33]}$

A study done by Guerra and Sherrill et al. conclude that Emphysema is associated with being underweight; asthma and chronic bronchitis are associated with being pre-obese or obese. The temporal sequence between smoking, abnormal BMI, and development of emphysema or chronic bronchitis is complex to assess. In contrast, the development of asthma seems to be temporally associated to a BMI $\geq 28$, as patients with asthma are more likely to be obese both after and before the onset of respiratory symptoms. ${ }^{[34]}$

\section{CONCLUSION}

In conclusion, our study showed that clear association was found between pulmonary function parameters and BMI in females with non-obstructive airway disease. Undernutrition is responsible for decrease in expiratory and inspiratory muscle mass, thus weakening the respiratory muscle. Weaker respiratory muscle diminishes the ventilatory capacity, whereas subsequent increase in weight may actually restrict the chest wall movement and that may causes significance changes the some parameters of pulmonary function.
Gorai et al

www.apjhs.com 


\section{REFERENCES}

1. Martins VJ, Toledo Florêncio TM, Grillo LP, do Carmo P Franco M, Martins PA, Clemente AP, et al. Long-lasting effects of undernutrition. Int $\mathbf{J}$ Environ Res Public Health 2011;8:1817-46.

2. World Health Organization. Obesity and Overweight. <http://www.who.int/dietphysicalacti vity/publications/facts/obesity/en/>(Versioncurre nt at April 10, 2008).

3. Global Initiative for Asthma. Global Strategy for Asthma Management and Prevention. Available at $<$ http://www.ginasthma.com/ReportItem.asp?11 $=2 \& 12=2 \&$ intId $=94>($ Version current at April 10, 2008).

4. Beuther DA, Sutherland ER. Overweight, obesity, and incident asthma: A meta-analysis of prospective epidemiologic studies. Am J Respir Crit Care Med. 2007; 175:661-66.

5. Ford ES. The epidemiology of obesity and asthma.J Allergy ClinImmunol.2005; 11:897-909.

6. Carmargo CA, Weiss ST, Zhang S, Willett WC, Speizer FE. Prospective study of body mass index, weight change, and risk of adult-onset asthma in women. Arch Intern Med. 1999; 159:2582-8.

7. Chen Y, Dales R, Tang M, Krewski D. Obesity may increase the incidence of asthma in women but not in men: longitudinal observations from the Canadian national population health surveys. Am J Epidemiol.2002; 155:191-7.

8. Chinn S, Jarvis D, Burney P. Relation of bronchial responsiveness to body mass index in the ERHS. Thorax.2002; 57:1028-33.

9. Schatcher LM, Salome CM, Peat JK, Wollcock AJ. Obesity is a risk for asthma and wheeze but not airway hyperresponsiveness. Thorax. 2001; $56: 4-8$.

10. Hancox RJ, Milne BJ, Poulton R, et al. Sex differences in the relation between body mass index and asthma and atopy in a birth cohort. Am J Respir Crit Care Med. 2005; 171:440 5.

11. Shaheen SO, Sterne JA, Montgomery SM, et al. Birth weight, body mass index and asthma in young adults. Thorax 1999; 54:396-402.

12. Young SY, Gunzenhauser JD, Malone KE, et al. Body mass index and asthma in the military population of the North Western United States. Arch Intern Med 2001; 161:1605-1611.

13. Garrow JS, Webster J. Quetelet's index as a measure of fatness. Int J Obes. 1985; 9(2): 14753.

14. Miller MR, Hankinson $J$, Brusasco $V$, et al. Standardization of spirometry. Eur Respir J. 2005; 25: 319-38.
15. Knudson RJ, Lebowitz M, Holberg CJ, Burrows B.Changes in the normal maximal expiratory flow-volume curve with aging. Am Rev Resp Dis. 1983; 127:725-34.

16. Figueroa-Muñoz JI, Chinn S, Rona RJ. Association between obesity and asthma in 4-11 year old children in the UK. Thorax 2001; 56:133-7.

17. Ong TJ, Mehta A, Ogston S, Mukhopadhyay S. Prediction of lung function in the inadequately nourished. Arch Dis Child 1998; 79:18-21.

18. Muralidhara DV, Bhat MR. Some aspects of the pulmonary functions in underweight and overweight human subjects. Thai J PhysiolSci 2007;20:3-7.

19. Wannamethee SG, Shaper AG, Whincup PH. Body fat distribution, body composition, and respiratory function in elderly men. Am J ClinNutr 2005; 82:996-1003.

20. Harik-Khan RI, Fleg JL, Wise RA. Body mass index and the risk of COPD. Chest 2002; 121:370-376.

21. Sahebjami H, Sathianpitayakul E. Influence of body weight on the severity of dyspnea in chronic obstructive pulmonary disease. Am J Respir Crit Care Med 2000; 161(3):886-890.

22. Filley GF, Beckwitt HJ, Reeves JT, et al. Chronic obstructive bronchopulmonary disease: II. Oxygen transport in two clinical types. Am J Med 1968; 44:26-38.

23. Jounieaux V, Mayeux I. Oxygen cost of breathing in patients with emphysema or chronic bronchitis in acute respiratory failure. Am J Respir Crit Care Med 1995; 152(6):2181-2184.

24. Donahoe M, Rogers RM, Wilson DO, et al. Oxygen consumption of the respiratory muscles in normal and in malnourished patients with chronic obstructive pulmonary disease.Am Rev Respir Dis 1989; 140:385-391.

25. Watson RA, Pride NB. Postural changes in lung volumes and respiratory resistance in subjects with obesity. J Appl Physiol. 2005; 98: 512-17.

26. Richard L.,Mary-Magdalene U. Nzekwu. The Effects of Body Mass Index on Lung volumes. Chest.2006; 130:827-33.

27. Cheryl M Salome, Gregory G. King and Norbert Berend: Physiology of obesity and effects on lung function. J Appl Physiol. 2010; 108: 206-11.

28. Biring M, Lewis M, Liu JT, Mohsenifar Z. Pulmonary physiologic changes of morbid obesity. Am J Med Sci. 1999; 318: 293-97.

29. Jenkin SC, Moxha J. The effects of mild obesity on lung function. Respir Med. 1991; 85:309-311. 
30. Collins, LC, Hoberty, PD, Walker, JF, et al The effect of body fat distribution on pulmonary function tests. Chest.1995; 107:1298-1302.

31. Mohammed Al Ghobain. The effect of obesity on spirometry tests among healthy non-smoking adults. BMC Pulmonary Medicine.2012; 12: 10.

32. Schoenberg JB, Beck GJ, Bouhuys A. Growth and decay of pulmonary function in healthy blacks and whites. Respir Physiol 1978; 33:367-93.

Conflict of Interest: None

Source of Support: Nil
33. Saxena Y, Saxena V, Dvivedi J, Sharma RK. Evaluation of dynamic function tests in normal obese individuals. Indian $\mathrm{J}$ Physiol Pharmacol 2008; 52:375-82.

34. Guerra S, Sherrill D, Bobadilla A, Martinez F, Barbee RA. The relation of body mass index to asthma, chronic bronchitis, and emphysema. Chest.2001;122 (4):1256-63. 